\title{
Do negativo social à transformação do real Aproximações entre Boal e Adorno
}

Flavio Sanctum ${ }^{1}$

\section{Resumo}

O presente artigo analisa o encontro da teoria de Theodor Adorno na prática do Teatro-Fórum, criada e desenvolvida pelo brasileiro Augusto Boal. Neste texto serão aproximados o conceito de Indústria Cultural e de "negativo social", presente na obra de Adorno em contraponto à prática contemporânea de Boal.

Palavras-Chave: Teatro-Fórum; Indústria Cultural; Arte Política

\begin{abstract}
This article analyzes the encounter of Theodor Adorno's theory in the practice of Theatre-Forum, created and developed by the Brazilian Augusto Boal. This text will approximate the concept of Cultural Industry and "social negative", present in the work Demirovic's text is Adorno's idea in counterpoint to Boal's contemporary practice.
\end{abstract}

Keywords: Theatre-Forum; Cultural Industry; Politic Art

\section{Introdução}

Na história das Artes Cênicas o Brasil recebe a herança do teatrólogo Augusto Boal que espalhou seu método artístico de transformação social em todos os continentes do mundo. O Teatro do Oprimido (TO) é hoje praticado em mais de setenta países, onde muitos artistas e ativistas sociais utilizam os jogos e técnicas criados ou sistematizados por Boal para redescobrir a arte adormecida e reprimida por uma sociedade capitalista, acelerada e opressiva.

Práticas como o Teatro Invisível ou o Teatro Jornal, experimentadas em tempos de ditadura e hoje ainda desenvolvidas pelos grupos de Teatro do Oprimido, fazem parte do "arsenal bélico", como dizia Boal, para a libertação do ser humano. Porém, a técnica mais praticada pelos multiplicadores do método é o Teatro-Fórum. Nessa vertente do Teatro do Oprimido o espectador, antes passivo e receptivo, é incentivado

\footnotetext{
${ }^{1}$ Curinga do Centro de Teatro do Oprimido e doutorando em Artes Cênicas pela UniRio.
} 
a subir no palco, entrar na cena antes apresentada e propor alternativas de mudança para o personagem oprimido. Indo um passo além do teatro dialético brechtiano, Boal sugere que o espectador saia de sua posição de espera e proponha saídas concretas para determinado problema.

Baseado no pensamento de Marx, Freire, Brecht e outros teóricos marxistas, Boal cria um método a serviço da liberdade do ser humano, da redescoberta do artista adormecido em cada um de nós com o objetivo de fazer da cultura e da arte, armas para a transformação da realidade.

O filósofo alemão Theodor Adorno, autor da Dialética do Esclarecimento e conceitualista da Indústria Cultural nos questiona sobre a arte engajada. Como crítico da obra épica brechtiana, Adorno não conseguia ver na arte política de sua época um instrumento a favor da revolução. Para ele somente a arte que negasse os elementos contidos na sociedade burguesa poderia ser crítica a essa mesma sociedade. Uma peça ou uma música que se utilizasse dos elementos burgueses não teria a força necessária para ser chamada de arte revolucionária, pois seguiria o mesmo raciocínio estético do modelo burguês. É difícil pensar qual produto artístico a serviço da revolução que agradaria esteticamente Adorno além do músico Schönberg.

Nosso desafio nesse texto é analisar o aspecto de "negativo social" na obra de arte proposto por Adorno e perceber se há possibilidades de aproximação com o que o filósofo diz com a prática do Teatro-Fórum. Utilizarei o texto de dois comentadores de Adorno para uma base teórica refletindo a partir do processo de criação de uma cena de Fórum, passando desde a oficina de sensibilização dos praticantes até o momento do produto final ser apresentado ao público. Pode haver alguma contiguidade entre Adorno e Boal?

\section{Processos do Teatro-Fórum como Atrito Social}

Para se construir uma cena de Teatro-Fórum o primeiro passo realizado é a produção de uma oficina de introdução ao Teatro do Oprimido. Sobre a coordenação do Curinga, que é o facilitador do método, os participantes executam diversos exercícios e jogos teatrais com a intenção de, aos poucos, irem percebendo que opressões vivenciaram e o que fizeram para minimizar os danos causados pelo opressor. Ao entrarem em contato com suas vivências, em momentos conflituosos não resolvidos, os participantes da oficina buscam histórias concretas de momentos em que se sentiram oprimidos e 
não conseguiram resolver a questão. Isto é, os participantes de uma oficina de Teatro-Fórum precisam compartilhar coletivamente situações reais, onde foram injustiçados e foram derrotados pelo opressor. O grupo escolhe qual história reverbera de forma mais forte na maioria, qual tema é mais urgente de ser discutido e transformado. A escolha de um tema para o Teatro-Fórum é uma escolha política! A partir desse recorte da realidade o grupo irá montar sua cena de TO, seguindo uma dramaturgia específica.

Adorno em alguns de seus textos nos fala sobre o negativo social que critica essa mesma sociedade. Seria como que algo que contribui para o mal social fosse a salvação da própria sociedade. O filósofo Oskar Negt explica:

Deve-se compreender assim o fato de o trabalho teórico consequente ser, para Adorno, uma forma de práxis decisiva, se não a mais humana, de modo que apenas o espírito de crítica do existente pode gerar faíscas de esperança no futuro, e isso somente pelo atrito forte com o material empírico.

(Duarte, 2004, pág. 103)

Para entender melhor esse pensamento adorniano sugiro acompanharmos a prática de Boal. Negt nos diz que "um atrito forte com o material empírico pode gerar faíscas de esperança no futuro". Supomos que esse "atrito" seja uma cena de Teatro-Fórum montada pelos participantes de uma oficina. Independente do estilo escolhido para a montagem da peça, comédia, drama, musical, a problemática vai estar apresentada na cena. Toda peça de Teatro-Fórum é uma provocação à sociedade - um problema que acontece na vida real, que aflige a um grupo de pessoas e provavelmente reflete em todo tecido social. Numa apresentação esse "atrito" encontrará o material empírico, que podemos entender como a realidade, os espectadores numa plateia. Nesse momento passamos do indivíduo para o coletivo. Aquela história contada por um sujeito pode reverberar em diferentes pessoas, em diferentes classes e contextos sociais. E parafraseando Adorno, a cena será um "outro" que critica a própria sociedade.

Muitas peças de Teatro-Fórum retratam temas difíceis de serem abordados fora do palco. Assuntos como violência doméstica, abuso sexual, homossexualidade são tabus e precisam de um mediador social em seu debate. Porém por outro lado, tais problemáticas são urgentes de serem discutidas e transformadas. No ponto de vista adorniano é através desses assuntos negativos, dessas questões rejeitadas pelo tecido social que podemos entender a sociedade onde estamos inseridos para futuramente transformá-la. "O apego forçado ao positivo é parte da pulsão de morte, e não a crítica do existente, que chama a desgraça pelo nome" (Duarte, 2004, p.104). 
Boal reforça a importância da investigação aprofundada quando busca em sua prática o efeito de ascese, para que, através do teatro, fossem entendidas as razões históricas de determinados problemas. A resolução de determinadas questões não dependem somente do desejo de mudança, mas sim de uma análise profunda das causas desses fenômenos.

Como a câmera do cineasta que, ao se afastar do ponto cêntrico do objeto sendo filmado, inclui elementos que o circundam, assim também, em um conflito particular, não devemos descer às suas singularidades, conjunturais, mas subir ao estrutural: do fenômeno à lei que o rege, às suas causas Ascese! (Boal, 2009, pág. 189)

E é essa ligação com a calamidade histórica que é defendida na teoria de Adorno, por trazer à tona assuntos não desejados, não discutidos, mas necessários para uma mudança social.

O decisivo aqui é a premente indicação de que uma cultura, como a que temos hoje, não pode ser isolada do contexto histórico e principalmente não pode ser separada da calamidade [unheil] histórica, que é ao mesmo tempo seu produto e seu resultado. (Duarte, 2004. Pág. 148)

E na prática proposta no Teatro do Oprimido avançamos de um conflito particular para uma discussão coletiva. E podemos confrontar o pensamento adorniano com o de Boal, em duas passagens que parecem complementar-se:

O aprofundamento no individuado eleva o poema lírico ao universal, por trazer a luz algo não deformado, não apreendido, ainda não subsumido, e assim antecipar espiritualmente algo de um estado em que nenhuma má universalidade, na verdade profundamente particular, amarra o outro, o humano. O construto lírico tem a esperança de encontrar o universal na individuação irrestrita (...) Mas essa universalidade do conteúdo lírico é essencialmente social. Só compreende o que o poema diz aquele que, na sua solidão, ouve a voz da humanidade. (Duarte, 2004, pág. 90)

Eu, se transforma em nós - extraordinário salto. Nós e os artistas, eu e nós plateia. Juntos, descobrimos a descoberta que fez o artista. Arte é, a um só tempo, individual e social: ao dizermos nós, descobrimos nosso abrangente eu. Digo eu, e somos nós. Podemos estar todos juntos diante de atores, bailarinos ou telas de cinema, ou podemos, solitários, observar um quadro ou escultura - a pluralização se opera, ainda que invisível. (Boal, 2009, pág. 112)

Esse processo de coletivização se dá, tanto no momento de criação da cena, quando a história não será mais da pessoa que a contou, mas agora de todo o coletivo, pois foi eleita para representar aquele grupo, como também no momento em que a cena chega ao público. Pode-se dizer que a plateia refaz o caminho percorrido pelos artistas, pois pode entrar na cena e se colocar enquanto protagonista, podendo transformar a estrutura cênica apresentada. Ao assistir uma sessão de Teatro-Fórum a plateia tem a oportunidade de se identificar com o protagonista da cena. Através da 
Dramaturgia empregada nos espetáculos o público cria uma empatia positiva ${ }^{2}$, colocando-se na situação do personagem oprimido e, desta forma, sente-se corresponsável pela busca de alternativas para o problema apresentado.

E Boal defende que nenhum espect-ator sai de uma sessão de Teatro-Fórum sem ser transformado, mexido de alguma maneira, pois o fato de ter presenciado a possibilidade de intervenção cênica abre precedentes para uma mudança na vida real.

Numa sessão de Teatro-Fórum, ninguém pode permanecer espectador no mau sentido dessa palavra. Mesmo que queira. Mesmo que se afaste, que fique só olhando, de longe. No Teatro-Fórum, todos os espect-atores sabem que podem parar o espetáculo no momento que desejarem. Que podem gritar "Para" e, democraticamente, dar sua opinião, teatralmente, em cena. Portanto, se escolhem não dizer nada, essa escolha já é uma participação. Para não dizer nada, o espectador tem que se decidir a não dizer nada: isso já é uma ação. (Boal, 1999, págs. 343, 344)

Adorno não apoiava uma arte engajada por entender que a própria matéria da arte é que deveria trazer a crítica ao mundo administrado e racionalizado e não buscar elementos fora da obra para fazer essa crítica. A experiência do artista na criação, a própria obra e o processo da plateia conseguir perpassar por sensações e emoções parecidas com as do artista na sua criação é que produzem a possibilidade de um debate social. Boal (2009) diz em sua Estética do Oprimido que: "O produto artístico - obra de arte - deve ser capaz de despertar ideias, emoções e pensamentos semelhantes aos que levaram o artista à sua criação." Nesse caso a arte precisa ser autônoma, ter um corpo próprio para provocar um choque social. Uma obra de arte precisa provocar ruptura nas regras fixas da sociedade para, assim, permitir que o espectador possa ter uma experiência estética que provoque fruição. Adorno acreditava ainda que a filosofia viesse como mediador da arte, a fim de possibilitar uma interpretação e uma análise da obra.

Para Adorno, em contrapartida, a filosofia tem a tarefa de conhecer o que não é mais, ou seja, de descobrir por que foram vedadas as possibilidades segundo as quais seria possível instituir uma vida melhor aqui e agora, respondendo por que a humanidade, como se lê no começo da Dialética do Esclarecimento, "em vez de entrar em um estado verdadeiramente humano, está se afundando em uma nova espécie de barbárie". (Duarte, 2004, pág. 140)

Essa experiência estética só seria possível se a obra provocasse uma não-identificação - o não-idêntico - ocasionando um "estranhamento" ao espectador. "A iden-

\footnotetext{
2 Quando digo empatia positiva é porque acredito numa negativa. Para Boal a empatia utilizada através da Tragédia Grega era para controlar a população de sua revolta política. Através de um sistema descrito por Aristóteles, onde a catarse era o objetivo final, a população era controlada e coagida a não seguir os atos dos heróis trágicos, com a consequência de sofrerem o mesmo que o herói sofreu na peça. Essa teoria defendida por Boal pode ser encontrada no livro Teatro do Oprimido e Outras Poéticas Políticas, editora Civilização Brasileira.
} 
tidade estética deve defender o não-idêntico que a compulsão à identidade oprime na realidade." (Adorno, 1970, pág.15) Quando a arte se afasta da vida real e traz uma leitura singular dessa realidade é possível analisar e criticar a sociedade. E essa crítica se dá por não estar envolvido com a obra - o envolvimento impossibilita a análise crítica. Boal, assim como Adorno, critica a mímesis ${ }^{3}$ por ser um elemento que imita a realidade, enquanto para haver crítica precisaria de uma representação do real. "A cópia do real reproduz aparências visíveis: duplica o óbvio. Artistas, nós mergulhamos no fundo do mar para depois pisar em terra firme." (Boal, 2009, pág.164)

Que as obras de arte, como mônadas sem janelas, «representem» o que elas próprias não são, só se pode compreender pelo fato de que a sua dinâmica própria, a sua historicidade imanente enquanto dialética da natureza e do domínio da natureza não é da mesma essência que a dialética exterior, mas se the assemelha em si, sem a imitar. (Adorno, 1970, pág. 16)

E ratificando o pensamento de Adorno, Boal diz que "uma das principais funções da Arte é revelar, tornar sensíveis e conscientes esses rituais teatrais cotidianos, espetáculos que nos passam desapercebidos, embora sejam formas potentes de dominação". (Boal, 2009, pág. 141)

Temos no Teatro-Fórum um bom exemplo de como uma obra de arte pode trazer a crítica a partir do lado "negativo" da sociedade, que dificilmente é apreciado. Nos espetáculos temos a representação da situação de opressão, onde cada participante coloca em cena imagens, sons e palavras que garantam - não uma cópia do que se passou na vida real - mas uma interpretação. O oprimido dá seu ponto de vista sobre o tema apresentado em forma de uma pergunta que não teve respostas, um problema não resolvido. Esse tema/espetáculo é levado a um público que pode interferir no caminho que a história pode tomar, tornando-se assim coautor da peça teatral.

\section{Referências}

ADORNO, T.W. Teoria Estética. Editora 70: Lisboa, 1970.

BOAL, Augusto. A Estética do Oprimido. Editora Garamond: Rio de Janeiro, 2009.

BOAL, Augusto. Jogos para Atores e não Atores. Editora Civilização Brasileira: Rio de Janeiro, 1999.

DUARTE, Rodrigo. KANGUSSU, Imaculada. FIGUEIREDO, Virginia (Orgs.) Theoria Aesthetica. Em comemoração ao centenário de Theodor Adorno. São Paulo: Escritos, 2004.

3 A mímesis é um processo social de identificação perversa, onde o sujeito, ao se identificar com o objeto, perde a sua distância crítica. A categoria da identidade, enquanto categoria essencial da arte concebida como mímesis, impossibilitaria pensar na arte como algo crítico, característica essencial para o pensamento adorniano. 